\section{Use of a PNA probe to block DNA-mediated PCR product formation in prokaryotic RT-PCR}

\author{
Mikkel Bender1,2, William E. Holben³, Søren J. Sørensen², \\ and Carsten S. Jacobsen ${ }^{1-3}$ \\ ${ }^{1}$ Geological Survey of Denmark and Greenland, Copenhagen, 2University of \\ Copenhagen, Copenhagen, Denmark, and ${ }^{3}$ University of Montana, Missoula, MT, USA
}

BioTechniques 42:609-614 (May 2007)

doi $10.2144 / 000112437$

A novel method eliminating DNA-mediated PCR product formation in reverse transcription PCR (RT-PCR) amplification of specific RNA sequences is described. The method exploits the higher melting temperature values of peptide nucleic acid (PNA)/DNA duplexes compared with DNA/DNA duplexes by binding a sequence-specific PNA probe to a genomic sequence immediately overlapping one of the PCR-primer attachment sites within the sequence of interest. Hybridization of the blocking probe precludes primer attachment to DNA without affecting attachment of the same primer to the reverse transcription-generated cDNA sequence. A four-step PCR cycle is used that allows the PNA probe to hybridize to the DNA strand at a higher temperature just prior to the primer annealing step.

\section{INTRODUCTION}

When analyzing RNA by reverse transcription PCR (RT-PCR) procedures, the elimination of contaminating DNA is of fundamental importance. Otherwise, the products obtained in PCR might originate from genomic DNA rather than specifically from cDNA produced from messenger RNA (mRNA). Removal of contaminating DNA is commonly achieved by treating samples with RNase-free DNase. However, DNase treatment is not well suited to a number of applications. The purpose of this study was to develop a new method to eliminate DNA-mediated product formation in RT-PCR by means of a probe specifically blocking amplification of contaminating DNA without affecting amplification of cDNA. Unlike eukaryotic mRNA, a poly(A) tail is not added to the $3^{\prime}$ end of bacterial mRNAs. This makes the design of RTPCR primers that target mRNA without targeting the corresponding DNA sequence impossible. However, unlike the corresponding chromosomal DNA sequence, the cDNA has two defined ends, one corresponding to either the RNA $5^{\prime}$ end at the transcription initiation site or an RNA $5^{\prime}$ end generated by RNA processing and a $3^{\prime}$ end generated by the primer used in the reverse transcription procedure. By contrast, the corresponding chromosomal DNA sequences continue beyond these points and have ambiguous ends based on the fragment length of each molecule. Herein, we demonstrate that sequence-specific blocking probes (1) can be designed, targeting the region immediately upstream of and proceeding through, these cDNA endsequences. Selective inhibition of PCR amplification of the chromosomal DNA is achieved by introducing a preprimer annealing step at a temperature sufficiently high to allow a peptide
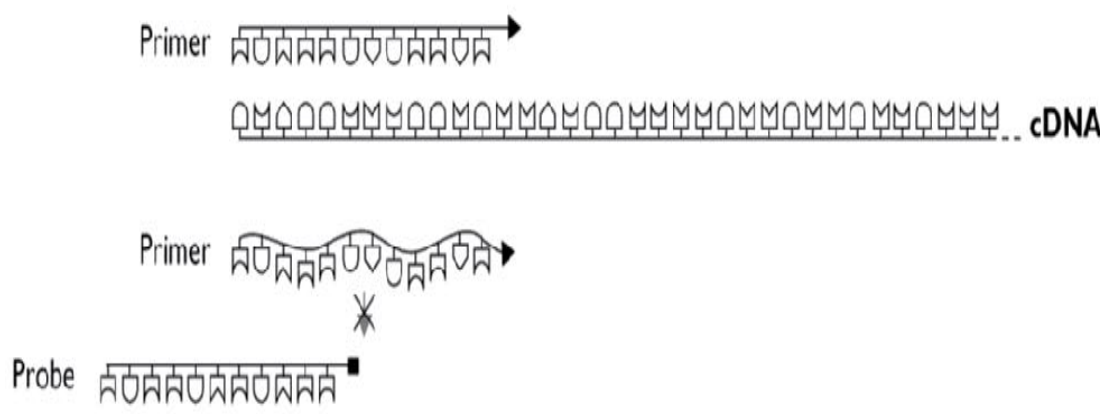

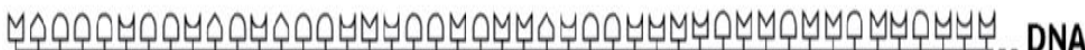

Figure 1. Peptide nucleic acid (PNA) inhibitor probe principle. After attachment of the probe to the genomic DNA sequence in the PCR pre-primer annealing step, PCR primers only anneal to the RNAderived cDNA in the subsequent primer annealing step. Thereby selective amplification of cDNA will be achieved. 
target. This strategy is not suited for the present purpose.

To our knowledge, this study represents the first attempt to block a specific PCR by placing a probe partly outside the sequence of interest. We show that the PNA probe inhibition assay is reproducible and that amplification of cDNA templates is not inhibited.

\section{MATERIALS AND METHODS}

\section{Strains and Culture Conditions}

Three bacterial strains, Escherichia coli SP308/pKJK10 (6), Pseudomonas putida OUS82 UCB55 (7), and Salmonella typhimurium LT2 (8) were used in this study. They were grown in appropriate media facilitating expression of the relevant genes.

\section{DNA Extractions}

DNA was extracted from pure cultures using commercial kits [Fast Soil DNA purification kit (BIO101, Vista, CA, USA) or UltraClean ${ }^{\mathrm{TM}}$ Soil DNA Extraction kit (MO-BIO, Solana Beach, CA, USA)] according to the manufacturer's instructions except that soil samples were replaced by pure culture samples.

\section{RNA Extractions}

Disposables and reagents were either certified RNase-free, or diethyl pyrocarbonate (DEPC)-treated $(0.1 \%$; Sigma, St. Louis, MO, USA) was added prior to autoclaving. RNA was extracted from approximately $10^{7}$ cells $\left(200 \mu \mathrm{L}, \mathrm{A}_{600}=0.1\right)$ P. putida OUS82 UCB55 overnight culture; from $300 \mu \mathrm{L}$ $S$. typhimurium overnight culture; and from $300 \mu \mathrm{L}$ E. coli SP308 cells either grown to stationary phase. Total RNA was extracted using the FastRNA ${ }^{\circledR}$ Pro Blue kit (BIO101) in accordance with the manufacturer's instructions.

\section{Optional DNase Treatment}

DNase treatment of P. putida and E. coli RNA preparations was performed using the amplification-grade DNase I kit (Sigma), and DNase treatment for S. typhimurium RNA preparations was performed using RQ1 RNase-free DNase (Promega, Madison, WI, USA); in both cases in accordance with the manufacturer's instructions.

\section{Primers and Blocking Probes}

The primers and blocking probes used in this study are shown in Table 1. All primers and PNA probes were custom-synthesized commercially and of high purity salt-free (HPSF ${ }^{\circledR}$ ) purity.

Two inhibition strategies were assayed. First, a terminal inhibition, where the probe and the forward primer were targeted at the $3^{\prime}$ end of the cDNA corresponding to the $3^{\prime}$ end of the mRNA, was designed. Primer gfpmb1-Fx was designed to target the leading strand sequence corresponding to the expected start sequence of the reverse-transcribed $g f p$ messenger 10 bases from the Pribnow box. Primer gfpmb2-R was placed 770 bases downstream of gfpmb1-Fx within the gfp gene. A blocking probe, PNAGFP1, was designed targeting the leading strand region immediately upstream of, and just overlapping, the gfpmb1Fx target. A mismatch was introduced in the region of the probe overlapping the $g f p$ cDNA sequence, because a PNA with the exact sequence could not be synthesized by our supplier. By this placement of the mismatch, the expected $T_{m}$ value of the PNA/cDNA hybrid (1 mismatch/10 nucleotides) was lowered, while the expected $\mathrm{T}_{\mathrm{m}}$ of the PNA/genomic DNA hybrid was affected to less extent ( 1 mismatch/18 nucleotides). An A to $\mathrm{G}$ base change was chosen, as a purine transition substitution was expected to have the least impact on $\mathrm{T}_{\mathrm{m}}$ (3).

In the second approach, internal inhibition, the probe PNA16S1reverse was designed to target the region amplified by the reverse primer used in the RT-PCR. The primers PRBA338F and 511R2 were used to amplify ribosomal RNA (rRNA) from E. coli. A $16 \mathrm{~S}$ rRNA encoding gene (in this case from E. coli) was selected because it is so widely targeted in phylogenetic and community-level analyses of microbial systems. This approach requires a two-step RT-PCR procedure, as having the PNA probe present in the reverse transcription step would inhibit cDNA synthesis. However, the general applicability of the developed method is greatly enhanced using the internal inhibition approach, as it liberates the researcher from design restrictions arising due to the transcription initiation-specific or termination signal-specific probe placement when the terminal PNA approach is used.

Primers invAF2 and invAR1 were designed to target the invA gene from Salmonella sp. involved in the invasiveness of Salmonella and has also been shown to be a diagnostic target for most Salmonella (9). PNAInvA1reverse is an internal-PNA probe designed to block DNA-based synthesis from the invAR1 primer.

Table 1. Primers and Probes Used in this Study

\begin{tabular}{|c|c|}
\hline Primer/Probe & Sequence \\
\hline gfpmb1-Fx & 5'-AATTGTGAGCGGATAACA-3' \\
\hline gfpmb2-R & 5'-AAGCTTATTTGTATAGTTCATCCATGC-3' \\
\hline PRBA338F & 5'-ACTCCTACGGGAGGCAGCAG-3' \\
\hline 511R2 & 5'-GCTGGCACGGAG-3' \\
\hline invAF2 & 5'-ACAGTGCTCGTTTACGAC-3' \\
\hline invAR1 & 5'-ACTGGTACTGATCGATAA-3' \\
\hline PNAGFP1 & 5'-H-ACTAGATTCGATTGTGAG-NH ${ }_{2}-3^{\prime}$ \\
\hline PNA16S1-reverse & 5'-H-GCGGCTGCTGG-NH ${ }_{2}-3^{\prime}$ \\
\hline PNAInvA1-reverse & 5'-H-AGACGA/CCTGGTACT-NH ${ }_{2}-3^{\prime}$ \\
\hline \multicolumn{2}{|c|}{ Boldface shows mismatched base in PNAGFP1. } \\
\hline
\end{tabular}




\section{Reverse Transcription}

$g f p$-targeted reverse transcription was performed using the GeneAmp ${ }^{\circledR}$ Gold RNA PCR Reagent kit (Applied Biosystems, Foster City, CA, USA) in accordance with the manufacturer's instructions. One microliter template RNA was reverse-transcribed in 20 $\mu \mathrm{L}$ reaction volume for $15 \mathrm{~min}$ at $45^{\circ} \mathrm{C}$. Salmonella RNA was reversetranscribed using SuperScript ${ }^{\mathrm{TM}}$ II (Promega) according to the manufacturer's instructions using $5 \mu \mathrm{L}$ RNA as template. Reverse transcription of $P$. putida and E. coli RNA was performed using ImProm-II ${ }^{\mathrm{TM}}$ Reverse Transcriptase (Promega) in accordance with the manufacturer's instructions.

\section{PNA Probe Pre-PCR Preparation}

PNAGFP1, PNA16S1-reverse, and PNAInvAR1-reverse stock solutions $(100 \mu \mathrm{M})$ were vortex mixed and then heated to $50^{\circ} \mathrm{C}$ for $10 \mathrm{~min}$ prior to addition to PCR mixtures.

\section{PCR Conditions}

gfp-targeted PCR was performed in a final volume of $25 \mu \mathrm{L}$, containing 17.5 $\mu \mathrm{L}$ or, when blocking probe was added, $15.5 \mu \mathrm{L}$ DNase/RNase-free

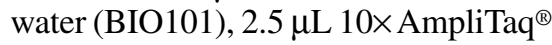
PCR buffer (Applied Biosystems), $0.125 \mu \mathrm{L} 12.5$ pmol each primer, 2.5 $\mu \mathrm{L} 25 \mu \mathrm{g}$ DNase-free bovine serum albumin (BSA; GE Healthcare, Uppsala, Sweden), $1 \mu \mathrm{L}$ GeneAmp $10 \mathrm{mM}$ dNTP mixture (Applied Biosystems), $0.125 \mu \mathrm{L}$ 0.6 U AmpliTaq polymerase (Applied Biosystems), and $1 \mu \mathrm{L}$ DNA. Blocking probe (PNAGFP1 or DNAGFP1) was added to a final concentration of $8.0 \mu \mathrm{M}$. Cycling conditions were $10 \mathrm{~min}$ at $95^{\circ} \mathrm{C}$ (initial denaturation), then 35 cycles of $30 \mathrm{~s}$ at $92^{\circ} \mathrm{C}$ (denaturation), $30 \mathrm{~s}$ at $63^{\circ} \mathrm{C}$ (blocking probe annealing), $30 \mathrm{~s}$ at $57^{\circ} \mathrm{C}$ (PCR primer annealing), and 1 min at $72^{\circ} \mathrm{C}$ (primer extension), and then 6 min of final extension at $72^{\circ} \mathrm{C}$ and final cooling at $4^{\circ} \mathrm{C}$.

For rRNA-targeted PCR, conditions were essentially the same except that $5 \%$ of the recovered RNA $(5 \mu \mathrm{L})$ was added as tempate, the PNA16S1reverse blocking probe, and PRBA338F and 511R2 primers were used, and the cycling conditions were $10 \mathrm{~min}$ at $95^{\circ} \mathrm{C}$, then 35 cycles of $30 \mathrm{~s}$ at $95^{\circ} \mathrm{C}$, $30 \mathrm{~s}$ at $58^{\circ} \mathrm{C}, 30 \mathrm{~s}$ at $53^{\circ} \mathrm{C}$, and $1 \mathrm{~min}$ at $72^{\circ} \mathrm{C}$, and then followed by $6 \mathrm{~min}$ at $72^{\circ} \mathrm{C}$ and final cooling at $4^{\circ} \mathrm{C}$.

PCR of cDNA was performed as described above except that $3 \mu \mathrm{L}$ of the cDNA product were used in a $50-\mu \mathrm{L}$ reaction containing $29.7 \mu \mathrm{L}$ or, when blocking probe was added, $25.7 \mu \mathrm{L}$ RNase-free water, $5 \mu \mathrm{L} 10 \times$ AmpliTaq PCR buffer, $3.2 \mu \mathrm{L} 25$ $\mathrm{mM} \mathrm{MgCl}_{2}, 3.7 \mu \mathrm{L} 10 \mathrm{mM} \mathrm{dNTP}$ mixture, $0.25 \mu \mathrm{L} 25$ pmol each primer, $0.5 \mu \mathrm{L} 2.5 \mathrm{U}$ AmpliTaq Gold ${ }^{\circledR}$ DNA polymerase (Applied Biosystems), and, where appropriate, $4.0 \mu \mathrm{L} 400 \mathrm{pmol}$ PNAGFP1. PCR cycling conditions were as indicated above for RNA-based amplification.

\section{Real-Time PCR of S. typhimurium invA cDNA}

PCRs were prepared in a total volume of $25 \mu \mathrm{L}$ by combining $13.25 \mu \mathrm{L}$ distilled water, $2.5 \mu \mathrm{L} 10 \times$ reaction buffer (Bio-Rad Laboratories, Hercules, CA, USA) $0.75 \mu \mathrm{L} \mathrm{MgCl}_{2}$, $1 \mu \mathrm{L} 5 \mathrm{mM}$ dNTP mixture (Invitrogen, Carlsbad, CA, USA), $0.5 \mu \mathrm{L} 10 \mathrm{pmol}$

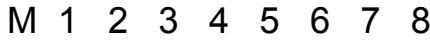

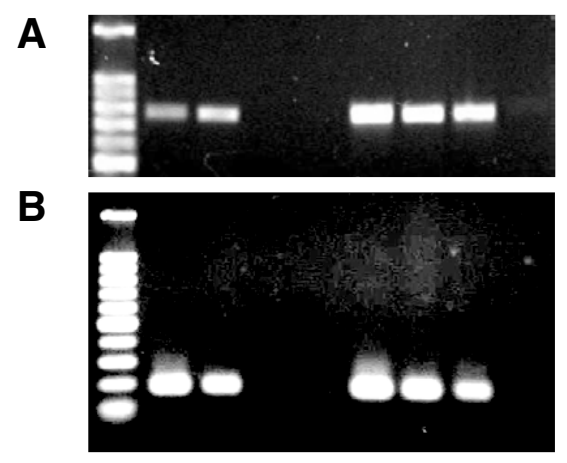

Figure 2. Ethidium bromide-stained reverse transcription PCR (RT-PCR) product bands using DNase treated (lanes 1-4) and untreated (lanes 5-8) total RNA extracts from (A) Pseudomonas putida OUS82 UCB55 and (B) exponentially growing cultures of Escherichia coli SP308/pKJK10. Reverse transcription enzyme was excluded from reactions $3,4,7$, and 8 , while in reaction $2,4,6$, and 8 , addition of the corresponding peptide nucleic acid (PNA) blocking probe [PNAGFP1 $(8.0 \mu \mathrm{M}$ final concentration) and PNA16S1-reverse $(2.0 \mu \mathrm{M}$ final concentration), respectively] to PCRs was performed. M, 100-bp ladder (Promega).
InvAF2 and InvAR1 primers, 0.25 $\mu \mathrm{L} \quad 1 / 1000$ diluted $\mathrm{SYBR}^{\circledR}$ Green (BioWhittaker, Rockland, ME, USA), and $0.25 \mu \mathrm{L}$ iTaq ${ }^{\mathrm{TM}}$ polymerase (BioRad Laboratories). PCR conditions in the iCycler $^{\circledR}$ (Bio-Rad Laboratories) were $10 \mathrm{~min}$ at $95^{\circ} \mathrm{C}$, then 35 cycles of $30 \mathrm{~s}$ at $95^{\circ} \mathrm{C}, 30 \mathrm{~s}$ at $67^{\circ} \mathrm{C}, 30 \mathrm{~s}$ at $55^{\circ} \mathrm{C}$, and $30 \mathrm{~s}$ at $72^{\circ} \mathrm{C}$, then followed by a melting program with a $0.5^{\circ} \mathrm{C}$ increase/min to $95^{\circ} \mathrm{C}$ between each measurement using FAM 490 filters, followed by cooling to $4^{\circ} \mathrm{C}$.

\section{RESULTS AND DISCUSSION}

\section{Efficiency of PNAGFP1 Blocking}

To test the effectiveness of the terminal and internal PNA blocking strategy, PCR assays were performed on duplicate samples of total RNA from exponentially growing $P$. putida OUS82 UCB55 cells constitutively transcribing the $g f p$ gene (Figure 2A) and exponentially growing E. coli SP308/pKJK10 (Figure 2B), respectively. The samples were each divided in two pairs. One pair of samples was reverse-transcribed immediately, while the other pair was treated with DNase prior to reverse transcription. Reverse transcriptase was excluded from one of the samples of each pair, and PCR was performed with and without the PNA probe for all samples.

In the terminal assay, the presence of contaminating DNA in the RNA extracts was indicated by production of ample PCR product with relative fluorescence intensity (RFI) equal to 2.32 in the sample that was not DNasetreated nor reverse-transcribed prior to PCR amplification (Figure 2A, lane 7). In this experiment, DNase treatment was shown to efficiently destroy contaminating DNA, since essentially no PCR product was produced from samples that were DNase-treated but not reverse-transcribed (Figure $2 \mathrm{~A}$, lanes 3 and 4; RFI $=0.01$ and 0.06 , respectively). A similar elimination of genomic DNA-derived PCR product was observed using the PNA blocking probe (Figure 2A, lane 8; RFI $=0.15$ ). By comparing lanes 1,2 , and 6 , it seems evident that the PNA probe had a beneficial effect on overall PCR 


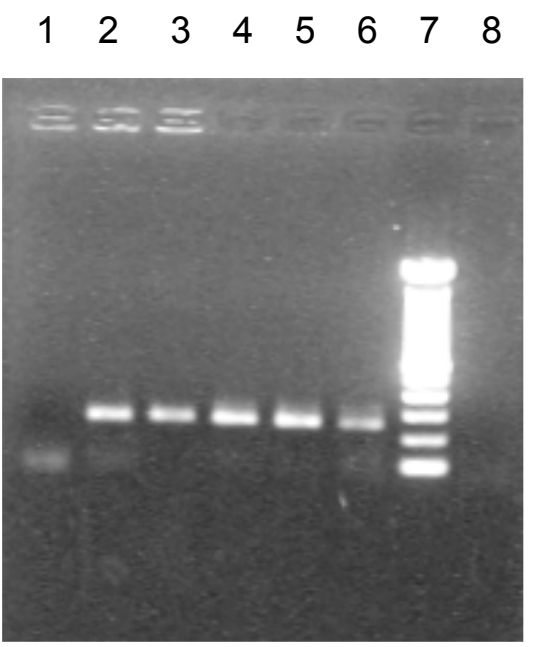

Figure 3. Representative bands originating from real-time PCR presented in Table 2. Lane 1 , nucleic acid extract, with no reverse transcriptase treatment but with addition of PNAInvA1reverse; lane 2, like lane 1, but with no peptide nucleic acid (PNA) added; lane 3, DNase-treated and reverse-transcribed with PNA; lane 4, like lane 3, but with no PNA addition; lane 5, reversetranscribed and PCR with PNA probe; lane 6, like lane 5, but without PNA addition; lane 7, 100-bp ladder; lane 8 , negative control.

performance (Figure 2A, lanes 1 and 2 ; RFI $=1.00$ and 1.42 , respectively). Collectively, these data indicate that the terminal PNA probe blocking approach eliminates the need for DNase treatment by physically blocking PCR primer binding to contaminating genomic DNA while enhancing PCR product formation through some as yet undefined and probably nonspecific mechanism. It has previously been shown that addition of nonspecific oligonucleotides (transfer RNA or tRNA) to PCR and RT-PCRs can increase product formation, presumably by loosely binding to excess primers during initial amplification cycles (10). The enhanced PCR performance observed in the current study after addition of PNAGFP1 may be caused by a similar effect. A similar terminal blocking system using a 34-mer 3' capped DNA probe as a blocking probe was not found to work efficiently (data not shown)

In the internal blocking assay, contaminating rRNA gene-encoding genomic DNA was present in both RNA extractions, as evidenced by production of ample PCR product where DNase and blocking probe were not used, even when the reverse transcriptase step was omitted (Figure 2B, lanes 5 and 7). DNase treatment effectively removed contaminating genomic DNA, preventing formation of PCR product where reverse transcription was omitted (Figure 2B, lanes 3 and 4). PNA blocking also eliminated PCR amplification from contaminating genomic DNA, even where DNase treatment was not performed (Figure 2B, lane 8). These results also indicate that internal PNA blocking approach is as effective as DNase treatment and thus can be applied where DNase treatment is impractical.

\section{Application of PNA Blocking to Structural Genes of Diagnostic Interest}

PNAInvA1-reverse block the formation of DNA-based PCR product in quantification of mRNA from the invA gene in S. typhimurium. To demonstrate the generality of the PNA blocking approach and extend its utility to quantification of expression of structural genes of diagnostic interest, we next applied the internal blocking approach to measure invA gene expression in $S$. typhimurium. To accomplish this, blocking of genomic DNA-derived

Table 2. Cycle Threshold Values for Real-Time PCR Amplification of Salmonella typhimurium invA Gene

\begin{tabular}{|c|c|c|c|c|c|c|}
\hline \pm PNA & & + PNA & & & -PNA & \\
\hline Replicate & 1 & 2 & 3 & 1 & 2 & 3 \\
\hline Direct nucleic acid extract (RNA and DNA) & N.A. & N.A. & N.A. & 26.9 & 26.9 & 27.9 \\
\hline $\begin{array}{l}\text { Reverse-transcribed after DNase treat- } \\
\text { ment }\end{array}$ & 29.3 & 29.7 & 28.9 & 28.5 & 28.8 & 29.7 \\
\hline $\begin{array}{l}\text { Reverse-transcribed no DNase treatment } \\
\text { PNA, peptide nucleic acid; N.A., not applicable. }\end{array}$ & 29.5 & 29.9 & 28.9 & 28.8 & 29.2 & 28.7 \\
\hline
\end{tabular}

invA PCR product formation was first optimized using primers invAF2 and invAR1 and the blocking probe PNAInvA1-reverse (Table 1) using blocking primer annealing temperatures between $60^{\circ}$ and $67^{\circ} \mathrm{C}$ and PCR primer annealing temperatures between $52^{\circ}$ and $67^{\circ} \mathrm{C}$ with genomic DNA from $S$. typhimurium as template. The final cycling protocol was selected based on near-optimal PCR product formation in the absence of PNAInvA1-reverse and no detectable product in the presence of PNAInvA1-reverse (Figure 3, lane 1). In Figure 3, real-time RT-PCR amplification of cDNA from the invA gene of $S$. typhimurium without PCR signal from the corresponding genomic DNA was accomplished using the PNA inhibitor probe PNAInvA1-reverse (Figure 3, lane 4). Real-time PCR analysis of the triplicate samples from DNase-treated samples with or without the addition of PNA probe provided comparable cycle threshold values (Table 2), indicating that the blocking probe does not inhibit the PCR process when true cDNA is the template.

Running extended numbers of amplification cycles for Salmonella sp. invA detection in certain cases resulted in signal arising from insufficiently suppressed DNA. Thus, the amount of PNA added must be directly determined for each detection design, since nonspecific binding of the PNA eventually could result in low concentrations of available PNA for hybridization and blocking in latter PCR cycles and subsequent generation of PCR product based on DNA. We have not optimized the needed concentration of PNA probe for excessively extended numbers of cycles in PCR, but in general, a lower number of target genes in a small amount of background DNA requires less blocking probe than would a large number of target genes in a rich and complex background of nontarget DNA.

Here we have suggested an alternative approach to eliminate formation of DNA-mediated RT-PCR products. We applied blocking probes with success in three different systems, $g f p$ mRNA, 16S rRNA, and invA mRNA. Strong blocking efficiency was found in all three systems. Similar PNA blocking systems could easily be developed for 
other RNA sequences, and the general applicability of the technique was demonstrated using both terminal and internal blocking strategies in three different systems. Additionally, the approach described herein could find application for the development of improved viral detection methods for RNA or DNA viruses based on strandspecific RT-PCR procedures.

\section{ACKNOWLEDGMENTS}

This work was supported by the research centre BIOPRO, financed by The Danish Research Council. C.S.J.'s sabbatical at the University of Montana was supported by the Danish Agricultural and Veterinarian Research Council and the Carlsberg Foundation.

\section{COMPETING INTERESTS STATEMENT}

M.B. and C.S.J. are co-inventors of "Method of Selective Detection of a Target Nucleic Acid," European patent no. 04738977.0-240, assigned to the Geological Survey of Greenland and Denmark. W.E.H. and S.J.S declare no competing interests.

\section{REFERENCES}

1. Thiede, C., E. Bayerdorffer, R. Blasczyk, B. Wittig, and A. Neubauer. 1996. Simple and sensitive detection of mutations in the ras proto-oncogenes using PNA-mediated PCR clamping. Nucleic Acids Res. 24:983-984.

2.Giesen, U., W. Kleider, C. Berding, A. Geiger, H. Orum, and P.E. Nielsen. 1998. A formula for thermal stability $(\mathrm{Tm})$ prediction of PNA/DNA duplexes. Nucleic Acids Res. 26:5004-5006.

3. Ørum, H., P.E. Nielsen, M. Engholm, R.H. Berg, O. Buchardt, and C. Stanley. 1993. Single base pair mutation analysis by PNA directed PCR clamping. Nucleic Acids Res. 21:5332-5336.

4. Cochet, O., E. Martin, W.H. Fridman, and J.L. Teillaud. 1999. Selective PCR amplification of functional immunoglobulin light chain from hybridoma containing the aberrant MOPC 21-derived V kappa by PNA-mediated PCR clamping. BioTechniques 26:818-820.

5. von Wintzingerode, F., O. Landt, A. Ehrlich, and U.B. Gobel. 2000. Peptide nucleic acid-mediated PCR clamping as a useful supplement in the determination of microbial diversity. Appl. Environ. Microbiol. 66:549557.
6.Sengeløv, G., K.J. Kristensen, A.H. Sørensen, N. Kroer, and S.J. Sørensen. 2001. Effect of genomic location on horizontal transfer of a recombinant gene cassette between pseudomonas strains in the rhizosphere and sphermosphere of barley seedlings. Curr. Microbiol. 42:160-167.

7. Tolker-Nielsen, T., U.C. Brinch, P.C. Ragas, J.B. Andersen, C.S. Jacobsen, and S. Molin. 2000. Development and dynamics of Pseudomonas sp. biofilms. J. Bacteriol. 182:6482-6489.

8. Hueck, C.J. 1998. Type III protein secretion systems in bacterial pathogens of animals and plants. Microbiol. Rev. 62:379-433.

9. Malorny, B., J. Hoorfar, C. Bunge, and R. Helmuth. 2003. Multicentervalidation of the analytical accuracy of Salmonella PCR: towards an international standard. Appl. Environ. Microbiol. 69:290-296.

10. Sturzenbaum, S.R. 1999. Transfer RNA reduces the formation of primer artefacts during quantitative PCR. BioTechniques 27:50-52.

Received 11 August 2006; accepted 29 January 2007.

Address correspondence to Carsten S. Jacobsen, Department of Geochemistry, Geological Survey of Denmark and Greenland, Øster Voldgade 10, DK1350 Copenhagen K, Denmark. e-mail: csj@geus.dk

To purchase reprints of this article, contact: Reprints@BioTechniques.com 